\title{
Effect of Speed and Boot Opening on Aerodynamics, Fuel Consumption, and $\mathrm{CO}_{2}$ Emission of Minibus
}

\author{
${ }^{* 1}$ Olusola A Oloruntoba and ${ }^{2}$ Adebunmi P Okediji \\ ${ }^{1}$ Department of Automotive Engineering, Elizade University, Ilara-Mokin, Nigeria \\ ${ }^{2}$ Department of Mechanical Engineering, Elizade University, Ilara-Mokin, Nigeria \\ \{olusola.oloruntoba | adebunmi.okediji\}@elizadeuniversity.edu.ng
}

ORIGINAL RESEARCH ARTICLE

Received: 13-JUN-2021; Reviewed: 10-OCT-2021; Accepted: 28-OCT-2021

http://dx.doi.org/10.46792/fuoyejet.v6i4.665

\begin{abstract}
Overspeeding and overloading contribute to road accidents. In developing countries, overloading is often indicated by open boot due to commercial transporters' motivation to carry an excess load to boost revenue. Therefore, there is a need to provide measures to control or eliminate the practice of overspeeding and overloading. This study aims to conduct a parametric study to determine the effect of vehicle speed and boot opening on the aerodynamics of airflow around a typical minibus, fuel consumption, and $\mathrm{CO}_{2}$ emission, and recommend optimum boot opening. Computational Fluid Dynamics is employed using the FLUENT ${ }^{\mathrm{TM}}$ program. Results show the existence of a wavy pattern for drag coefficient, fuel consumption, and $\mathrm{CO}_{2}$ emission concerning boot opening. Furthermore, two boot opening regions exist: $0^{\circ} \leq$ $\theta \leq 35^{\circ}$ and $35^{\circ}<\theta \leq 90^{\circ}$. The first region exhibits low prediction error (maximum of $7.25 \%$ ) and better fit of regression model to FLUENT data. The first region also has lower susceptibility to exhibit handling instability. Therefore, boot opening around $\theta=9.30^{\circ}$ is recommended as the optimum boot opening, to ensure minimum fuel consumption and $\mathrm{CO}_{2}$ emissions, improve handling and safety. The developed regression models could inform regulatory bodies' formulation and implementation of policies to mitigate road accidents.
\end{abstract}

Keywords- Boot Opening, $\mathrm{CO}_{2}$ emission, Fuel Consumption, Pressure drag, Total Drag, Minibus, Viscous Drag

\section{INTRODUCTION}

$\mathrm{R}^{\mathrm{s}}$ educed vehicle aerodynamic drag, due to modification of vehicle shape, has been shown to enhance vehicle performance, fuel efficiency, reduction in air pollution, handling and safety, aesthetics, and passenger comfort (Gaylard et al., 2014; Le Good et al., 2011; Howell et al., 2014; Huminic \& Huminic, 2017; Mukut \& Abedin, 2019; Schuetz, 2016). Indiscriminate vehicle shape modifications occur in developing countries where commercial vehicle operators prop vehicle boots to accommodate more loads. The interest is to make more revenue, with little or no regard for vehicle aerodynamics, fuel consumption, and Carbon dioxide $\left(\mathrm{CO}_{2}\right)$ emission.

In particular, aerodynamics affects vehicle performance in terms of propulsion force, acceleration, and deceleration. These also directly impact on fuel consumption to achieve required vehicle propulsion, acceleration, and deceleration. Finally, $\mathrm{CO}_{2}$ is emitted in relation to the quantity of fuel consumed. Since $\mathrm{CO}_{2}$ is a greenhouse gas, with a labelled potential of negatively affecting the environment, controlling the emission of this gas into the atmosphere should be encouraged. Other emissions from vehicles have also been demonstrated to have adverse effects on the environment, and particularly, human health (Wang et al., 2020; Wargo et al., 2006; Wolfe et al., 2020). Examples of these emissions include Nitrogen Oxides (NOx), Carbon Monoxide (CO), particulates, among others.

\section{${ }^{*}$ Corresponding Author}

Section C- MECHANICAL/MECHATRONICS ENGINEERING \& RELATED SCIENCES Can be cited as:

Oloruntoba O.A. and Okediji A.P. (2021): Effect of Speed and Boot Opening on Aerodynamics, Fuel Consumption, and $\mathrm{CO}_{2}$ Emission of Minibus, FUOYE Journal of Engineering and Technology (FUOYEJET), 6(4), 380-385. http://dx.doi.org/10.46792/fuoyejet.v6i4.665
In general, aerodynamic drag coefficient is inversely proportional to the square of vehicle speed. And fuel consumption and $\mathrm{CO}_{2}$ emission can be related to aerodynamic drag using analytical relations (Environmental Protection Agency, 2018; Jazar, 2008). Annual report data from the Nigerian Federal Road Safety Corps (FRSC) is used presently to establish the importance of minibus boot opening to aerodynamics, fuel consumption, and $\mathrm{CO}_{2}$ emission. The FRSC road marshals generally categorise loaded vehicles with open boots as overloading. Based on published annual reports between the period of 2012 and 2016, the FRSC attributed about $0.84 \%$ of all cases of crashes on Nigerian roads to overloading, while $18.65 \%$ and $31.32 \%$ of all cases are linked to loss of control and speed violation respectively (FRSC, 2012, 2013, 2014, 2015, 2016). Overloading (or open boot), coupled with speed violation, can lead to severe road crashes.

Previous studies have shown that improvement of vehicle performance and fuel efficiency is typically achieved by proper modifications of vehicle shape (Altaf et al., 2014; Fourrié et al., 2011; Ha et al., 2011; Hsu \& Davis, 2010; Leuschen \& Cooper, 2009; Mohamed-Kassim \& Filippone, 2010; Nayeri et al., 2009; Zhang et al., 2019). Arbitrary modification of vehicle shape may lead to increase in aerodynamic drag and fuel consumption. In a similar way, variation of boot opening is a modification to the shape of a vehicle from the automaker's operational design shape, which could have negative or positive effects on the vehicle's aerodynamic characteristics, vehicle performance, fuel consumption, and quantity of Carbon dioxide $\left(\mathrm{CO}_{2}\right)$ emitted by the vehicle into the ambient (Environmental Protection Agency, 2018).

In this study, a parametric study based on vehicle speed and boot opening is carried out to determine 
aerodynamic drag coefficients, fuel efficiency, and carbon dioxide emission from a typical minibus used for commercial transportation of passengers and goods. The minibus studied is the 2020 TOYOTA HiAce. A numerical study is carried out via the well-established Computation Fluid Dynamics (CFD) approach using the widely used and robust ANSYSTM FLUENTTM.

\section{MOdel DEsCRIPTION}

\subsection{Problem Description}

This study was carried out using TOYOTA ${ }^{\mathrm{TM}} \mathrm{HiAce}^{\mathrm{TM}}$ (2020 model) minibus shown in Figure 1. The overall length $L$, width $W$ and height $H$ of the minibus are $5.915 \mathrm{~m}, 1.950 \mathrm{~m}$, and $1.990 \mathrm{~m}$ respectively. A Computer Aided Drawing (CAD) model of the minibus was developed using ANSYS ${ }^{\mathrm{TM}}$ DesignModeler ${ }^{\mathrm{TM}}$. Vehicle Geometry for CFD simulations is generally simplified by removing complex features which could complicate meshing and numerical simulation (Huminic \& Huminic, 2017; Zhang et al., 2019). Figures 2 and 3 show a typical TOYOTA $^{\mathrm{TM}} \mathrm{HiAce}^{\mathrm{TM}}$ with an open boot.

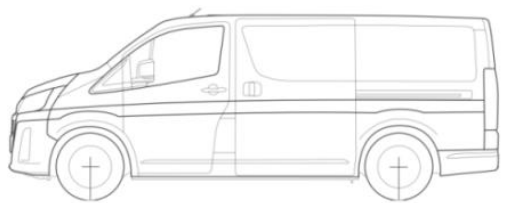

Fig. 1: TOYOTA $^{\mathrm{TM}} \mathrm{HiAce}^{\mathrm{TM}}$ minibus; 2020 model (Source: Toyota, 2020)

A sufficiently large numerical wind tunnel is employed to simulate a realistic aerodynamic flow of air around the vehicle (Ashton \& Revell, 2015; Zhang et al., 2019). Details of the numerical wind tunnel and simplified TOYOTA ${ }^{\mathrm{TM}}$ $\mathrm{HiAce}^{\mathrm{TM}}$ minibus configuration are provided in Figure 4.

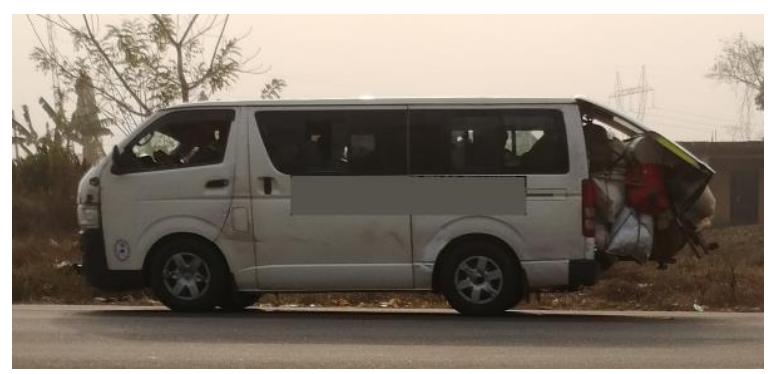

Fig. 2: Typical TOYOTA ${ }^{\mathrm{TM}} \mathrm{HiAce}^{\mathrm{TM}}$ minibus with open boot.

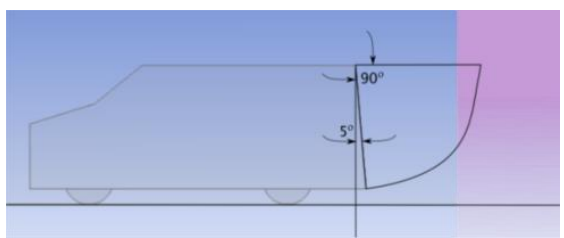

Fig. 3: Simplified TOYOTA ${ }^{\mathrm{TM}} \mathrm{HiAce}^{\mathrm{TM}}$ minibus with geometrical illustration of boot opening at $\boldsymbol{\theta}=\mathbf{5}^{\mathbf{0}}$ and $\boldsymbol{\theta}=\mathbf{9 0}^{\mathbf{0}}$; base geometry is at $\boldsymbol{\theta}=\mathbf{0}^{\mathbf{0}}$.

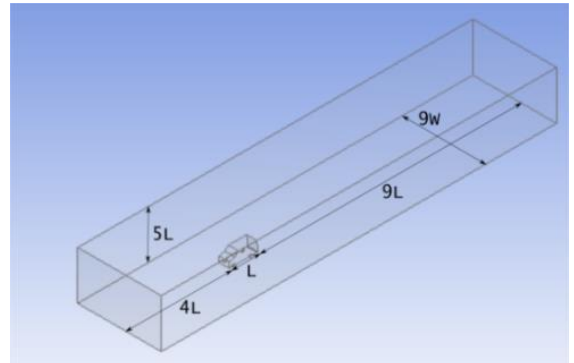

Fig. 4: Numerical wind tunnel and simplified TOYOTA ${ }^{\mathrm{TM}} \mathrm{HiAce}^{\mathrm{TM}}$ minibus; dimension shown in terms of vehicle length $(L)$ and width (W).

\subsection{GOVERNING EQUATIONS}

The governing equations (Navier-Stokes equations or NSE) for aerodynamic flow of air around a vehicle consist of the mass and momentum conservation equations shown in Equations (1) and (2) respectively (ANSYS, 2016; Zhang et al., 2019).

$$
\frac{\partial \rho}{\partial t}+\nabla \cdot(\rho \vec{v})=0
$$

where the symbols $\vec{v}, \rho, P, \overline{\bar{\tau}}$ and $\rho \vec{g}$ represent velocity vector, density, static pressure, stress tensor, and gravitational body force respectively. Turbulence is modelled using the SST $k-\omega$ viscous model (ANSYS, 2016a; Zhang et al., 2019a).

$$
\frac{\partial(\rho \vec{v})}{\partial t}+\nabla \cdot(\rho \vec{v} \vec{v})=-\nabla P+\nabla \cdot(\overline{\bar{\tau}})+\rho \vec{g}
$$

\subsection{BOUNDARY CONDITIONS}

The numerical wind tunnel consists of velocity inlet and pressure outlet conditions respectively. The ground is modelled as a moving wall boundary with the same velocity as the velocity inlet. The top and sidewalls of the numerical wind tunnel are treated as symmetry planes. There are a total of 95 cases; these consist of inlet velocity varying between $60 \mathrm{~km} / \mathrm{h}$ and $140 \mathrm{~km} / \mathrm{h}$ at an increment of $20 \mathrm{~km} / \mathrm{h}$, and boot opening varying between $0^{\circ}$ and $90^{\circ}$ at an increment of $5^{0}$.

\subsection{MESHING}

The volume mesh employed for CFD simulations in this study is polyhedral since this type of mesh have cells that are in contact with many (poly) neighbouring cells (Figure 5), leading to improved and robust gradient approximations, quick convergence, and reduced computational time, when compared with tetrahedral and hexahedral mesh types (Sosnowski et al., 2018).

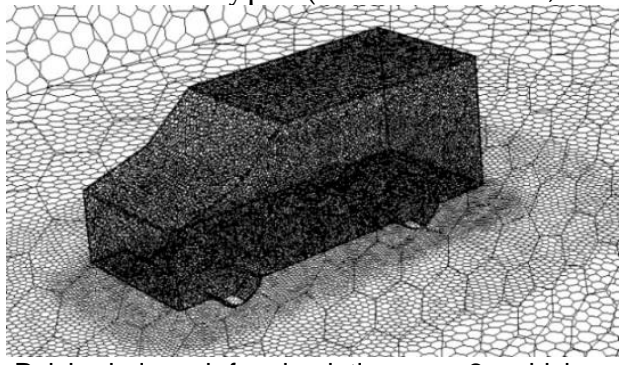

Fig. 5: Polyhedral mesh for simulation case 2 ; vehicle speed is $\boldsymbol{v}=\mathbf{6 0} \mathbf{~} \mathbf{m} / \boldsymbol{h}$ and boot opening is $\boldsymbol{\theta}=\mathbf{5}^{\mathbf{0}}$; minimum mesh quality for the 95 cases studied is 0.1847 . 


\subsection{SimULATION}

The set of governing equations (NSE), Equations (1) and (2) are discretised numerically using the finite volume (FV) scheme. The incompressible governing equations are solved using the Density-Based solver in ANSYS ${ }^{\mathrm{TM}}$ FLUENT $^{\mathrm{TM}}$. Absolute velocity formulation and steadystate flow condition are employed. The SST $k-\omega$ viscous model is applied to capture turbulence flow. The Implicit solution method is employed to achieve pressure-velocity coupling. The gradient and flow of spatial discretisation used are Least Square Cell Based and Second Order Upwind respectively. First Order Upwind is applied for Specific Dissipation Rate.

\subsection{Drag Coefficient}

Drag coefficient (Equation 3) is determined using the general vehicle performance model (Zhang \& Mi, 2011), with negligible inertia and road slope.

$$
C_{d}=\frac{2 F_{d}}{\rho A_{F} v^{2}}
$$

\subsection{Fuel CONSUMPTION}

The fuel efficiency of a vehicle moving at constant speed is approximated as shown in Equation (4) (Jazar, 2008). Assumed values for these symbols are given in Table (1).

$$
q=\frac{F_{d}}{\eta_{e} \eta_{t} \rho_{f} H^{*}}
$$

Table 1. Numerical values applied to obtain fuel consumption of minibus for 95 cases studied.

\begin{tabular}{cccc}
\hline S/N & Symbol & Value & Unit \\
\hline 1 & $\eta_{e}$ & 0.32 & dimensionless \\
2 & $\eta_{t}$ & 0.94 & dimensionless \\
3 & $\rho_{f}$ & 740 & $\mathrm{~kg} / \mathrm{m}^{3}$ \\
4 & $H^{*}$ & 46.7 & $\mathrm{MJ} / \mathrm{kg}$ \\
\hline
\end{tabular}

\subsection{CARBon DIOXIDE $\left(\mathrm{CO}_{2}\right)$ EMISSION}

Carbon dioxide emission from vehicles has a direct relationship with fuel consumption (Environmental Protection Agency, 2018). The Green Vehicle Guide by the United State Environmental Protection Agency (EPA) gives $8,887 \mathrm{~g}$ of $\mathrm{CO}_{2}$ per gallon of gasoline (Environmental Protection Agency, 2018). This estimate translates to $2.347 \times 10^{6} \mathrm{~g}$ per cubic metre. Given that the value of fuel consumption is known, carbon dioxide emission is expressed as shown in Equation (5).

$$
\varepsilon_{\mathrm{CO}_{2}}=\left(2.347 \times 10^{6}\right) q
$$

\section{RESULTS AND DISCUSSION 3.1 Drag Coefficient}

Figure 6 shows the scatter plot of pressure drag coefficient $\mathrm{C}_{\mathrm{p}}$ of the minibus as a function of boot opening at vehicle speed $60 \mathrm{~km} / \mathrm{h}, 80 \mathrm{~km} / \mathrm{h}, 100 \mathrm{~km} / \mathrm{h}, 120 \mathrm{~km} / \mathrm{h}$ and $140 \mathrm{~km} / \mathrm{h}$. The plot reveals that $\mathrm{C}_{\mathrm{p}}$ exhibits a wavy variation with boot opening $\left(0^{0} \leq \theta \leq 90^{\circ}\right)$. A fourth order polynomial regression model is therefore obtained, from the data plotted in Figure (6), to predict $C_{p}$ as shown in Equation (6); the coefficients are $\alpha_{1}=6 e^{-8}, \alpha_{2}=$ $-1 e^{-5}, \alpha_{3}=5 e^{-4}, \alpha_{4}=-7 e^{-3}$, and $\alpha_{5}=0.5791$; where $R^{2}=0.8191$

$$
C_{p, r}=\alpha_{1} \theta^{4}+\alpha_{2} \theta^{3}+\alpha_{3} \theta^{2}+\alpha_{4} \theta+\alpha_{5}
$$

Observations from this study agree with previous studies which show that reduction of aerodynamics drag (and in effect, improvement of vehicle performance and fuel efficiency) depends on proper modification of vehicle shape (Altaf et al., 2014; Fourrié et al., 2011; Ha et al., 2011; Hsu \& Davis, 2010; Leuschen \& Cooper, 2009; MohamedKassim \& Filippone, 2010; Nayeri et al., 2009; Zhang et al., 2019). Within the limit $0^{0} \leq \theta \leq 90^{\circ}$, two minimum values of $C_{p}$ which occur at $\theta=9.50^{\circ}$ and $\theta=74.05^{\circ}$ are 0.550 and 0.546 respectively. The maximum value of $C_{p}$ is 0.613 at $\theta=41.44^{0}$. The value of $C_{p}$ at base geometry (i.e., $\left.C_{p}=0.579\right)$ is $5.01 \%$ and $5.70 \%$ higher than the minimum values of $C_{p}$ at $\theta=9.50^{\circ}$ and $\theta=74.44^{\circ}$ respectively, but $5.87 \%$ lower than the maximum value of $C_{p}$ at $\theta=41.44^{\circ}$. Also, boot inclinations in the regions of $\theta=41.44^{\circ}$ and $\theta>80^{\circ}$ should be avoided to prevent the occurrence of high values of $C_{p}$.

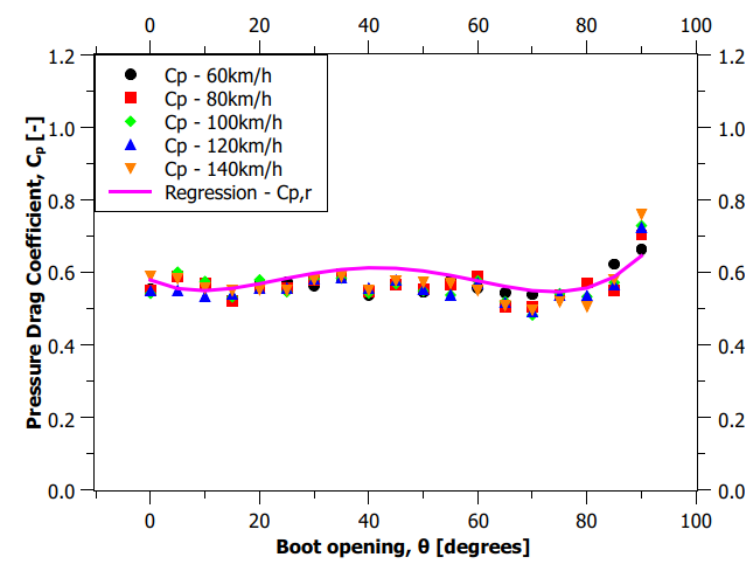

Fig. 6: Pressure drag coefficient of minibus at various vehicle speeds as a function of boot opening.

A linear regression model is obtained from Figure 7 to predict $C_{v}$ as a function of $\theta$. The linear regression is shown in Equation (7). The coefficients of the regression model are $\gamma_{1}=8 e^{-5}, \gamma_{2}=0.0102 ;$ where $R^{2}=0.9563$

$$
C_{v, r}=\gamma_{1} \theta+\gamma_{2}
$$

The scatter plot of the calculated total drag coefficient $C_{d}$ versus boot opening is shown in Figure 8 which is similar to the plot for $C_{p}$. A polynomial expression model to predict $C_{d}$ as a function of $\theta$ is given in Equation (8). The coefficients of the regression model are $\beta_{1}=6 e^{-8}, \beta_{2}=$ $-1 e^{-5}, \beta_{3}=5 e^{-4}, \beta_{4}=-6.9 e^{-3}$, and $\beta_{5}=0.5895$; where $R^{2}=0.8217$.

In comparison with $C_{p}, C_{v}$ has negligible effect on $C_{d}$. Therefore, the analysis carried for $C_{p}$, in terms of occurrence of two minimum values and one maximum value of $C_{p}$ also holds for $C_{d}$. But several parameters have changed due to the contribution of $C_{v}$ in Equation: $C_{d}=$ 
$C_{p}+C_{v}$. The two minimum values of $C_{d}$ now occur at $\theta=$ $9.30^{\circ}$ and $\theta=73.85^{\circ}$ are 0.561 and 0.564 respectively.

Similar to observations reported by Huminic and Huminic (Huminic \& Huminic, 2017) for Ahmed body, Figure 8 shows that observed $C_{d}$ data as well as $C_{d, r}$ predicted by the fourth order regression model slightly decreases from an intercept value at $\theta=0^{0}$ to a minimum value at about $\theta \cong\left(10^{0}-15^{\circ}\right)$ before peaking at $\theta \cong 35^{\circ}$, the corresponding minimum and maximum values obtained in this study for $C_{d, r}$ occur at $\theta=9.30^{\circ}$ and $\theta=$ $41.84^{\circ}$ respectively. This can be attributed to geometric similarity between the widely used benchmark, the Ahmed hatchback, and minibus with an open boot.

$$
C_{d, r}=\beta_{1} \theta^{4}+\beta_{2} \theta^{3}+\beta_{3} \theta^{2}+\beta_{4} \theta+\beta_{5}
$$

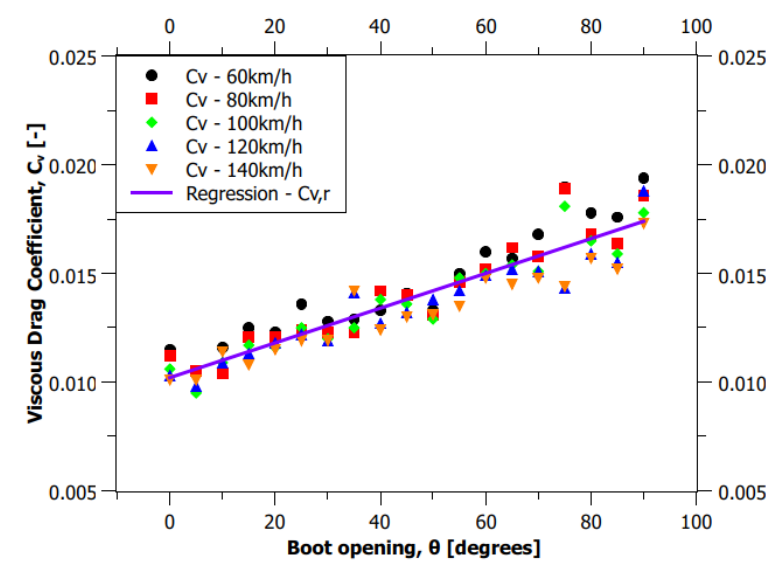

Fig. 7: Viscous drag coefficient of minibus at various vehicle speeds as a function of boot opening.

Therefore, the concluding wavy pattern for the range $35^{\circ}<\theta \leq 90^{\circ}$ can be approximated using $C_{d, r}$ as provided in Equation (8).

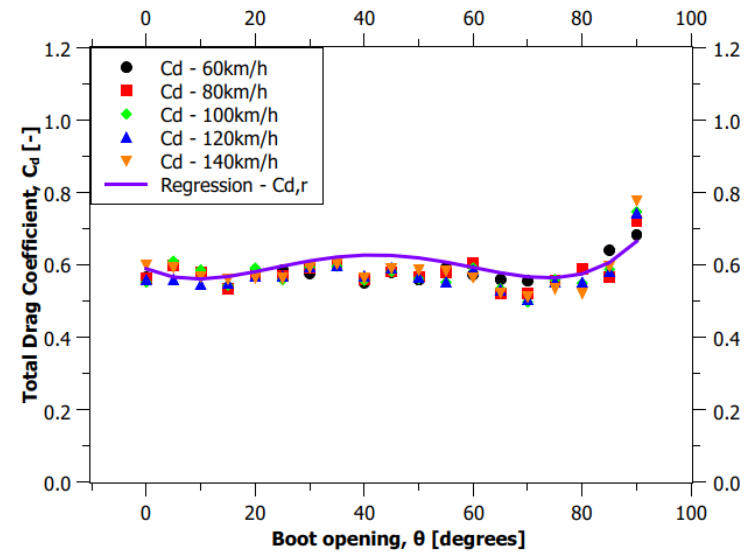

Fig. 8: Total drag coefficient of minibus at various vehicle speeds as a function of boot opening.

\subsection{FUEL CONSUMPTION}

Linear relationships exist between fuel consumption and total drag coefficient for vehicle speeds $60 \mathrm{~km} / \mathrm{h}, 80 \mathrm{~km} /$ $h, 100 \mathrm{~km} / \mathrm{h}, 120 \mathrm{~km} / \mathrm{h}$, and $140 \mathrm{~km} / \mathrm{h}$. The generic linear regression model is given in Equation (9). The coefficients and $R^{2}$ values for the regression models are provided in Table 2.

$$
q_{r}=\vartheta_{1} C_{d}+\vartheta_{2}
$$

Figure 9 presents the plot of fuel consumption $q$ data versus boot opening $\theta$ for minibus speed at $60 \mathrm{~km} / \mathrm{h}$, $80 \mathrm{~km} / \mathrm{h}, 100 \mathrm{~km} / \mathrm{h}, 120 \mathrm{~km} / \mathrm{h}$, and $140 \mathrm{~km} / \mathrm{h}$. At low vehicle speed, such as $60 \mathrm{~km} / \mathrm{h}$, fuel consumption appears constant with variation in boot opening. This constancy of fuel consumption with respect to boot opening, however, progressively follows the observable wavy pattern as vehicle speed approaches $140 \mathrm{~km} / \mathrm{h}$. It should be noted that wavy pattern observed for $C_{p}$ and $C_{d}$ also exists for $q$, but becomes more pronounced at higher vehicle speed.

Table 2. Coefficients and $\boldsymbol{R}^{\mathbf{2}}$ values for the linear regression models for predicting fuel consumption as a function of total drag coefficient

\begin{tabular}{ccccc}
\hline S/N & $\begin{array}{c}\text { Speed } \\
(\boldsymbol{k m} / \boldsymbol{h})\end{array}$ & $\boldsymbol{\vartheta}_{\mathbf{1}}$ & $\boldsymbol{\vartheta}_{\mathbf{2}}$ & $\boldsymbol{R}^{\mathbf{2}}$ \\
\hline 1 & 60 & $6.8001 \mathrm{e}^{-2}$ & $+8.3465 \mathrm{e}^{-5}$ & 0.9998667 \\
2 & 80 & $1.2116 \mathrm{e}^{-1}$ & $-2.5480 \mathrm{e}^{-6}$ & 0.9999996 \\
3 & 100 & $1.8975 \mathrm{e}^{-1}$ & $-2.2787 \mathrm{e}^{-4}$ & 0.9992717 \\
4 & 120 & $2.7348 \mathrm{e}^{-1}$ & $-4.3316 \mathrm{e}^{-4}$ & 0.9992567 \\
5 & 140 & $3.7220 \mathrm{e}^{-1}$ & $-6.1507 \mathrm{e}^{-4}$ & 0.9994277 \\
\hline
\end{tabular}

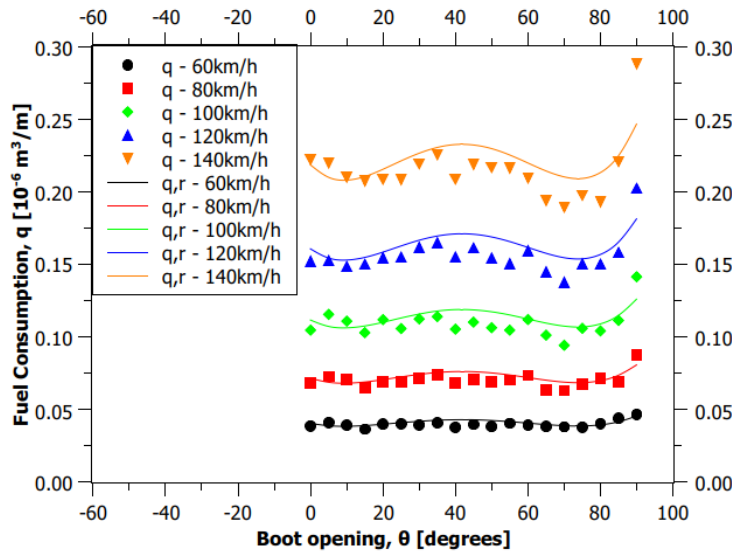

Fig. 9: Fuel consumption of minibus at various vehicle speeds as a function of boot opening.

In order to express vehicle fuel consumption as a function of boot opening, Equations (8) and (9) are combined as shown in Equation (10). The plot of vehicle fuel consumption as a function of boot opening is plotted to match the numerical data obtained as shown in Figure (8).

$$
q_{r}=\vartheta_{1}\left(\beta_{1} \theta^{4}+\beta_{2} \theta^{3}+\beta_{3} \theta^{2}+\beta_{4} \theta+\beta_{5}\right)+\vartheta_{2}
$$

The wavy pattern already identified in this study also reflects on fuel consumption, with the same maximum $\left(\theta=41.84^{\circ}\right)$ and minimum $\left(\theta=9.30^{\circ}\right.$ and $\left.\theta=73.84^{\circ}\right)$ values boot openings obtained for pressure and total drag coefficients since the wavy variation of total drag coefficient with boot opening (i.e., $C_{d}$ and $C_{d, r}$ as functions of $\theta$ ) has been employed to obtain expression for fuel consumption. Based on the numerical data obtained from ANSYSTM FLUENTTM simulations in this study, fuel consumption attained the lower of the two minimum values around $\theta=73.84^{\circ}$. But regression model prediction error in the range $35^{\circ}<\theta<90^{\circ}$ is high, attaining a maximum value of $14.44 \%$ at $\theta=90^{\circ}$ and 
exhibiting pronounced scattered data due to highly turbulent flow. This large prediction error limits the application of Equation (10) in predicting fuel consumption in the region of $\theta>35^{\circ}$. In comparison, the maximum prediction error of the regression model is $7.25 \%$ and exhibits a better fit of data to model in the boot opening range $0^{0} \leq \theta \leq 35^{0}$. Furthermore, the boot projections (Figure 3) are observed to vary between $1.105 \mathrm{~m}$ and $3.095 \mathrm{~m}$ for boot openings ranging between $\theta=0^{\circ}$ and $\theta=90^{\circ}$ respectively. From vehicle handling consideration of overloaded vehicle, boot opening at $\theta=$ $9.30^{\circ}$ would have centre of gravity (c.g.) closer to the geometric centre of a vehicle compared to openings in the vicinity of $\theta=73.84^{\circ}$, and would exhibit better vehicle handling characteristics in manoeuvring corners and potentially improve safety.

Therefore, boot opening in the vicinity of $\theta=9.30^{\circ}$ is recommended as the optimum boot inclination. This recommendation does not, however, take into account the effect of non-uniform load arrangement as is obtained for most overloaded minibuses (Figure 2). Vehicle fuel consumption at vehicle speed other than $60 \mathrm{~km} / \mathrm{h}$, $80 \mathrm{~km} / \mathrm{h}, 100 \mathrm{~km} / \mathrm{h}, 120 \mathrm{~km} / \mathrm{h}$ and $140 \mathrm{~km} / \mathrm{h}$ may be estimated via the application of interpolation or extrapolation techniques. Although extrapolation is expected to give fairly accurate estimates it must however be employed with caution. The prediction accuracy of Equation (10) can be improved by taking into account the effect of vehicle speed on total drag coefficient.

\subsection{CaRbon Dioxide $\left(\mathrm{CO}_{2}\right)$ EmISSION}

Figure 10 presents the plot of $\mathrm{CO}_{2}$ emission $\varepsilon_{\mathrm{CO}_{2}}$ data versus boot opening $\theta$ at $60 \mathrm{~km} / \mathrm{h}, 80 \mathrm{~km} / \mathrm{h}, 100 \mathrm{~km} / \mathrm{h}$, $120 \mathrm{~km} / \mathrm{h}$ and $140 \mathrm{~km} / \mathrm{h}$. A similar pattern (Equation 11) is observed as for fuel consumption since a linear relationship exists between the two parameters (i.e., $q$ and $\left.\varepsilon_{\mathrm{CO}_{2}}\right)$.

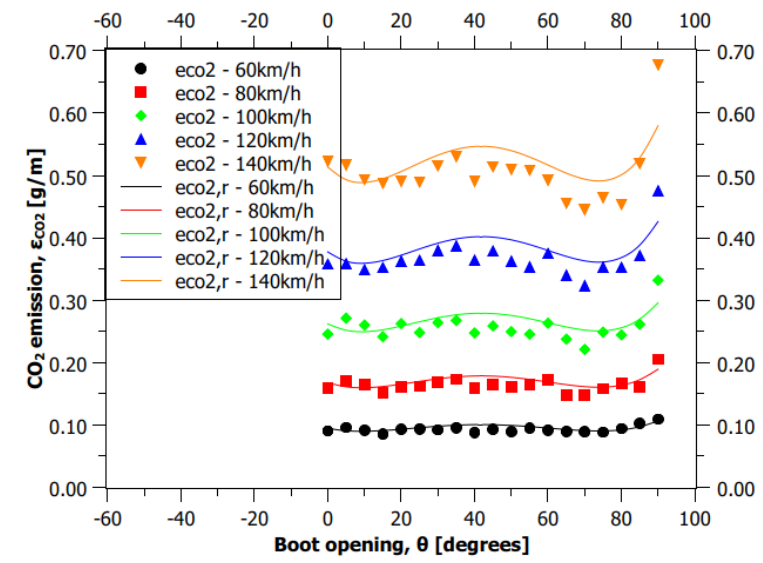

Fig. 10: Carbon dioxide emission of minibus at various vehicle speeds as a function of boot opening.

Emission as a function of boot opening as shown in Equation (11)

$$
\varepsilon_{C O_{2}, r}=\mu_{1}\left(\beta_{1} \theta^{4}+\beta_{2} \theta^{3}+\beta_{3} \theta^{2}+\beta_{4} \theta+\beta_{5}\right)+\mu_{2}
$$

Since a similar wavy pattern is obtained for $\mathrm{CO}_{2}$ emission as with fuel consumption, with the maximum (at $\theta=$ $41.84^{\circ}$ ) and minimum (at $\theta=9.30^{\circ}$ and $\theta=73.84^{\circ}$ ) values, similar conclusions and implications apply. That is, boot opening in the vicinity of $\theta=9.30^{\circ}$ is recommended as the optimum boot inclination, to ensure minimum $\mathrm{CO}_{2}$ emissions, improve vehicle handling and safety.

Percentage error observed in the application of Equation (11) to estimate $\mathrm{CO}_{2}$ emission based on boot opening, with a maximum absolute error of $14.443 \%$. Estimation of $\mathrm{CO}_{2}$ emission for vehicle speed other than $60 \mathrm{~km} / \mathrm{h}, 80 \mathrm{~km} / \mathrm{h}$, $100 \mathrm{~km} / \mathrm{h}, 120 \mathrm{~km} / \mathrm{h}$ and $140 \mathrm{~km} / \mathrm{h}$ may be estimated following the suggested procedure provided for vehicle fuel consumption.

\section{ConClusions}

Effect of speed and boot opening on aerodynamics, fuel consumption, and $\mathrm{CO}_{2}$ emission of minibus was studied using ANSYS ${ }^{\mathrm{TM}}$ FLUENT $^{\mathrm{TM}}$ program. Speed range of 60 $\mathrm{km} / \mathrm{h}$ to $140 \mathrm{~km} / \mathrm{h}$ at interval of $20 \mathrm{~km} / \mathrm{h}$, and boot opening of $0^{0}$ to $90^{\circ}$ at interval of $5^{0}$ were employed. The following findings are made:

- Pressure and total drag coefficients (i.e., $C_{p}$ and $C_{d}$ respectively) as well as fuel consumption and $\mathrm{CO}_{2}$ emissions ( $q$ and $\varepsilon_{\mathrm{CO}_{2}}$ ) exhibit slightly wavy pattern with boot opening variation in the range $0^{\circ} \leq \theta \leq 90^{\circ}$. Regression models have been obtained in this study as $C_{p, r}, C_{d, r}, q_{r}$ and $\varepsilon_{C O_{2}, r}$ to predict pressure, total drag coefficients, fuel consumption and $\mathrm{CO}_{2}$ emissions respectively. Minimum values of $C_{p, r}, C_{d, r}, q_{r}$ and $\varepsilon_{\mathrm{CO}_{2}, r}$ occur in the vicinity of boot openings $\theta=9.30^{\circ}$ and $\theta=73.84^{\circ}$.

- Two regions are identified; the first region (range $0^{0} \leq$ $\theta \leq 35^{\circ}$ ), exhibits low prediction error (maximum value of $7.25 \%$ ) and better fit of regression model to ANSYS $^{\mathrm{TM}}$ FLUENT $^{\mathrm{TM}}$ data, when compared-with the second region (range $35^{\circ}<\theta \leq 90^{\circ}$ ). Furthermore, the first region has less susceptibility to exhibit vehicle handling instability due to overloading. Therefore, boot opening in the vicinity of $\theta=9.30^{\circ}$ is recommended as the optimum boot inclination, to ensure minimum fuel consumption and $\mathrm{CO}_{2}$ emissions, improve vehicle handling and safety.

- The resulting quantitative and qualitative relationships between speed, open boot, fuel consumption and carbon dioxide could effectively inform the formulation and implementation of policies by road transport regulatory bodies aimed at mitigating road crashes.

\section{RECOMMENDATIONS}

Detailed experimental validation should be carried out to further improve confidence levels in the proposed methodology. Furthermore, minibus geometry should be modelled to capture side mirror, silencer, and other components which are usually ignored to simplify CFD analysis.

\section{NomenClature}

$\begin{array}{lll}\theta & = & \text { Boot opening, [degree] or [0] or [deg] } \\ v & = & \text { Vehicle or minibus speed, }[\mathrm{km} / \mathrm{h}]\end{array}$




\begin{tabular}{|c|c|c|}
\hline$C_{p}$ & $=$ & Pressure drag coefficient [-] \\
\hline$C_{d}$ & $=$ & Total drag coefficient [-] \\
\hline$C_{v}$ & $=$ & Viscous drag coefficient [-] \\
\hline$q$ & $=$ & Fuel consumption $\left[10^{-6} \mathrm{~m}^{3} / \mathrm{m}\right]$ \\
\hline$\varepsilon_{\mathrm{CO}_{2}}$ & $=$ & $\mathrm{CO}_{2}$ emission $[\mathrm{g} / \mathrm{m}]$ \\
\hline$C_{p, r}$ & $=$ & Regression model to predict $C_{p}[-]$ \\
\hline$C_{d, r}$ & $=$ & Regression model to predict $C_{d}[-]$ \\
\hline$C_{v, r}$ & $=$ & Regression model to predict $C_{v}[-]$ \\
\hline$q_{r}$ & $=$ & Regression model for $q_{r}\left[10^{-6} \mathrm{~m}^{3} / \mathrm{m}\right]$ \\
\hline$\varepsilon_{C_{2}, r}$ & $=$ & Regression model for $\varepsilon_{\mathrm{CO}_{2}}[\mathrm{~g} / \mathrm{m}]$ \\
\hline$\alpha_{i}$ & $=$ & Coefficient of $C_{p, r}$ model [deg-1 $\left.{ }^{-1}\right]$ \\
\hline$\beta_{i}$ & $=$ & Coefficient of $C_{d, r}$ model [deg-1] \\
\hline$\gamma_{i}$ & $=$ & Coefficient of $C_{v, r}$ model [deg-1] \\
\hline$\vartheta_{i}$ & $=$ & $q_{r}$ model coefficient $\left[\mathrm{deg}^{-1} 10^{-6} \mathrm{~m}^{3} / \mathrm{m}\right]$ \\
\hline$\mu_{i}$ & $=$ & Coefficient of $\varepsilon_{C O_{2}, r}$ model $\left[\mathrm{deg}^{-1} \mathrm{~g} / \mathrm{m}\right]$ \\
\hline$\eta_{e}$ & $=$ & Engine efficiency [-] \\
\hline$\eta_{t}$ & $=$ & Transmission efficiency [-] \\
\hline$\rho_{f}$ & $=$ & Density of fuel $\left[\mathrm{kg} / \mathrm{m}^{3}\right]$ \\
\hline$F_{d}$ & $=$ & Vehicle propulsion force $[\mathrm{N}]$ \\
\hline$A_{F}$ & $=$ & Vehicle frontal area $\left[\mathrm{m}^{2}\right]$ \\
\hline$C_{r}$ & $=$ & Wheel rolling resistance [-] \\
\hline$H^{*}$ & $=$ & Thermal value of fuel $[\mathrm{MJ} / \mathrm{kg}]$ \\
\hline Subscr & $t i$ & Instances of a variable; $1,2,3$ \\
\hline
\end{tabular}

\section{REFERENCES}

Altaf, A., Omar, A. A., \& Asrar, W. (2014). Passive drag reduction of square back road vehicles. Jnl. of Wind Engineering and Industrial Aerodynamics, 134, 30-43. https://doi.org/10.1016/j.jweia.2014.08.006

ANSYS. (2016). ANSYS FLUENT Theory Guide (17.0). ANSYS, Inc.

Ashton, N., \& Revell, A. (2015). Comparison of RANS and DES Methods for the Driver Automotive Body Comparison of RANS and DES Methods for the Driver Automotive Body. SAE International. https://doi.org/10.4271/2015-01-1538

Environmental Protection Agency. (2018). Greenhouse Gas Emissions from a Typical Passenger Vehicle. Green Vehicle Guide. https://www.epa.gov/greenvehicles/greenhouse-gas-emissionstypical-passenger-vehicle

Fourrié, G., Keirsbulck, L., Labraga, L., \& Gilliéron, P. (2011). Bluffbody drag reduction using a deflector. Experiments in Fluids, 50(2), 385-395. http://dx.doi.org/10.1007/s00348-010-0937-6.

FRSC. (2012). Federal Road Safety Corps: 2012 Annual Report.

FRSC. (2013). Federal Road Safety Corps: 2013 Annual Report.

FRSC. (2014). Federal Road Safety Corps: 2014 Annual Report.

FRSC. (2015). Federal Road Safety Corps: 2015 Annual Report.

FRSC. (2016). Federal Road Safety Corps: 2016 Annual Report.

Gaylard, A. P., Oettle, N., Gargoloff, J., \& Duncan, B. (2014). Evaluation of Non-Uniform Upstream Flow Effects on Vehicle Aerodynamics. SAE International, 692-702. https://doi.org/10.4271/2014-01-0614

Good, G. Le, Johnson, C., Clough, B., \& Lewis, R. (2011). The Aesthetics of Low Drag Vehicles. SAE International. https://doi.org/10.4271/2011-37-0016

Ha, J., Jeong, S., \& Obayashi, S. (2011). Drag reduction of a pickup truck by a rear downward flap. International Journal Automotive Technology, 12(3), 369-374. http://dx.doi.org/10.1007/s12239-0110043-7.

Howell, J., Garry, K., \& Holt, J. (2014). The Aerodynamics of a Small Car Overtaking a Truck Tata Motors European Technical Centre. SAE International. https://doi.org/10.4271/2014-01-0604

Hsu, F. H., \& Davis, R. L. (2010). Drag Reduction of Tractor-Trailers Using Optimized Add-On Devices. Journal of Fluids Engineering, 132(8). http://dx.doi.org/10.1115/1.4001587.
Huminic, A., \& Huminic, G. (2017). Aerodynamic Study of a Generic Car Model with Wheels and Underbody Diffuser. International Journal of Automotive Technology, 18(3), 397-404. https://doi.org/10.1007/s12239

Jazar, R. N. (2008). Vehicle Dynamics: Theory and Application. Springer Science+Business Media, LLC.

Leuschen, J., \& Cooper, K. R. (2009). Summary of Full-Scale Wind Tunnel Tests of Aerodynamic Drag-Reducing Devices for Tractor-Trailers. In The Aerodynamics of Heavy Vehicles II: Trucks, Buses, and Trains (pp. 451-462). Springer. https://doi.org/10.1007/978-3-540-85070-0_41

Mohamed-Kassim, Z., \& Filippone, A. (2010). Fuel savings on a heavy vehicle via aerodynamic drag reduction. Transportation Research Part D: Transport and Environment, 15(5), 275-284. http://dx.doi.org/10.1016/j.trd.2010.02.010.

Mukut, M. I., \& Abedin, M. Z. (2019). Review on Aerodynamic Drag Reduction of Vehicles. International Journal of Engineering Materials and Manufacture, 4(1), 1-14.

Nayeri, C. N., Haff, J., Greenblatt, D., Loefdahl, L., \& Paschereit, C. O. (2009). Drag Reduction on a Generic Tractor-Trailer using Active Flow Control in Combination with Solid Flaps. In The Aerodynamics of Heavy Vehicles II: Trucks, Buses, and Trains (pp. 179-191). Springer. http://dx.doi.org/10.1007/978-3-540-850700_14.

Schuetz, T. (2016). Aerodynamics of Road Vehicles. SAE International.

Sosnowski, M., Krzywanski, J., Grabowska, K., \& Gnatowska, R. (2018). Polyhedral meshing in numerical analysis of conjugate heat transfer. 02096, 4-9.

Toyota. (2020). Toyota HiAce Specification Data.

Wang, H., Wu, Y., Zhang, K. M., Zhang, S., Baldauf, R. W., Snow, R., Deshmukh, P., Zheng, X., He, L., \& Hao, J. (2020). Evaluating mobile monitoring of on-road emission factors by comparing concurrent PEMS measurements. Science of The Total Environment, 736, 139507. https://doi.org/10.1016/j.scitotenv.2020.139507

Wargo, J., Wargo, L., Alderman, N., \& Brown, D. R. (2006). The Harmful Effects of Vehicle Exhaust: A Case for Policy Change. Environment and Human Health Inc, North Haven, CT

Wolfe, M. K., McDonald, N. C., Arunachalam, S., Baldauf, R., \& Valencia, A. (2020). Impact of school location on children's air pollution exposure. Journal of Urban Affairs, 0(0), 1-17. https://doi.org/10.1080/07352166.2020.1734013

Zhang, C., Bounds, C. P., Foster, L., \& Uddin, M. (2019). Turbulence Modeling Effects on the CFD Predictions of Flow over a Detailed Full-Scale Sedan Vehicle. Fluids, 4(148), 1-28. https://doi.org/10.3390/fluids4030148

Zhang, X., \& Mi, C. (2011). Vehicle Power Management: Modelling, Control and Optimization. Springer. https://doi.org/10.1007/978-085729-736-5 